\title{
PROBLEMAS DO ENSINO DA ANTROPOLOGIA *
}

\section{Egon Schaden}

Se um professor de antropologia aceita a incumbência de falar sôbre problemas do ensino de sua disciplina, espera-se que, além de apontar dificuldades e falhas, proponha soluções baseadas na experiência de seus trabalhos didáticos. Parte dos problemas, entretanto, foge quase inteira. mente ao raio de ação do docente, pois decorre da estrutura do nosso ensino universitário e da posição da antropologia em face do que dela esperam, de um lado, os estudantes que freqüentam os cursos e, do outro, a própria scciedade. Daí a falta de equilíbrio e até de correspondência satisfatória entre os múltiplos problemas que depara o professor e as sugestões que possa fazer no sentido de resolvê-los. O mais que dêle se há de exigir é que procure, sempre que possível, dar formulaçóes precisas̆, relativas a situações concretas. A discussão teórica de aspectos metodológicos do ensino da antropologia, embora talvez mais sedutora, seria menos adequada aos objetivos essencialmente práticos desta Reunião. Por essa razão, quero cingir-me de preferência ao ensino antropológico nos cursos universitários brasileiros atuais.

Nem por isso poderei evitar referências, embora ligeiras, a questões de ordem teórica, pois tôda discussão relativa ao ensino da Ciência do Homem deve não somente ter em vista as finalidades e a organização dos institutos que a incluam em seus currículos, mas atender também à situação peculiar da antropologia no conjunto das ciências, quer do ponto de vista sistemático, quer do histórico. Além disso, é evidente que muitos problemas de ensino decorrem da posição teórica e metodológica assumida e defendida pelo professor.

Cumpre, pois, tomar consciência, por exemplo, das vantagens e desvantagens das "escolas" em antropologia. Pergunta-se: Deve ou não o ensino orientar-se no sentido de favorecer a filiação dos futuros especialistas a determinada escola, do tipo das que se tem formado no decorrer do último século, como o sejam a evolucionista (ou néo evolu. cionista), a histórico-cultural, a funcionalista, a tipológica e outras mais? Para dar resposta satisfatória à questio, ter-se-á em mente a função e o perigo das escolas no desenvolvimento das ciências. Mormente nas fases iniciais dêste processo, em que, aceito talvez como legítimo o objeto próprio e específico, mas não se dispondo ainda de método adequado ao sミu tratamento, os princípics formulados são postcs à prova através de fundamentação teórica e aplicação prática nos trabalhos de pesquisa. Formam-se assim as escolas como grupos de cientistas crentes da superioridade e excelência de determinada orientação. Cada uma se reduz a 
uma família de experimentadores de um método, congregados, com freqüência, em tôrno duma personalidade de relêvo, que propugne o novo método em oposição aos anteriores. $\mathrm{Na}$ atitude crítica em face dêstes, a nova escola encontra estímulo para o seu trabalho e, às vêzes, a sua maior contribuição para a ciência. Os resultados que julga ter obtido passarão, por sua vez, pelo crivo das escolas que lhe seguirem e que é comparável ao fundo da agulha de que fala o Evangelho. À medida, porém, que acalmam as polêmicas - e delas tivemos muitas entre os antropólogos - insiste-se menos nos pontos de divergência entre uma corrente e outra do que na plataforma comum e na possibilidade de se conjugar o que de positivo haja na contribuição de cada uma. E vê-se, como não raro se tem visto, que os pontos de contacto entre as facçöes são mais numerosos e bem mais expressivos do que se ousaria supor $€$ que, longe de se excluirem uns aos outros, os métodos (e as correspondentes teorias) se completam de modo fértil e com vantagem. Deixa-se de insistir nas diferenças, outrora exageradas, para se encontrar um possível denominador comum. Foi o que se deu na maioria das ciências naturais, na sociologia e em outras disciplinas. E é o que se está esboçando na antropologia, que se aproxima de um ponto - como o demonstrou eloqüentemente o congresso reunido em Viena há pouco mais de um ano - em que a oposição entre as escolas deixa de desempenhar a função que lhe tem cabido até o presente, abrindo-se nova fase, em que se alcançará, não um método único (o que seria estagnação), mas uma conjunção de teorias e métodos diferentes na investigação de determinados problemas.

O ensino universitário da antropologia no Brasil é novo e não se prende, por conseguinte, a nenhum tradicionalismo; êste fato é explorado vantajosamente pelo professor que se proponha formar antropólogos no sentido pleno da palavra, cientistas que não se deixem levar pela bitola de perspectivas unilaterais. $\mathrm{E}$ o próprio espírito antropológico, antítese de estreitos nacionalismos, auxilia-o também a não preferir cegamente as contribuições de um país às de outro, mas a aproveitá-las tôdas no momento oportuno, e a não forçar, por isso mesmo, a criação de uma "teoria antropológica brasileira" sem que haja razões objetivas para tal. A antropologia brasileira há de constituir-se - é êste o primeiro ponto - através de um ensino que não deixe de dar aos alunos uma visão crítica da antropologia universal e que, pondo em relêvo o valor de cada uma das teorias existentes, previna a formação prematura e talvez desnecessária de novas escolas.

Passemos ao segundo problema. Quanto à delimitação teórica do objeto antropológico em face do de outras ciências, é sabido que se pode invocar uma série de argumentos a favor ou contra os critérios adotados nas diferentes universidades. O mesmo vale, é claro, para a subdivisão da Ciência do Homem em um número maior ou menor de disciplinas constitutivas. Não se chegará nunca, a não ser por convenção, a um acôrdo ia êste respeito. Tanto é certo, porém, que a antropologia - quaisquer que sejam os dados que utilize e qualquer o método de 
interpretação - não tem a unidade de seu objeto na uniformidade do material, mas na perspectiva em que se coloca para analisá-lo e que decorre de objetivo bastante bem definido: o de explicar o lugar do homem na natureza ou, em outros termos, a compreensão científica da natureza humana. Qualquer que seja o enquadramento do ensino antropológico neste ou naquele currículo universitário, quaisquer os fins explícitos a que se destinem os cursos e o programa a ser desenvolvido (quer se trate de cursos de antropologia física ou de antropologia cultural), não se perderá de vista êsse objetivo, sob pena de se desvirtuar - sentido fundamental dêsse ramo do saber humano. Como, porém, o caráter da atual organização universitária do Brasil não exclui o perigo, cumpre insistir um pouco neste aspecto.

$\mathrm{Na}$ Faculdade de Filosofia, Ciências e Letras da Universidacie de São Paulo, a Cadeira de Antropologia faz parte do Departamento de Scciologia e Antropologia, que congrega, além dela, as duas Cadeiras de Sociologia e a de Política. O ensino da Antropologia foi aí instituido em agôsto de 1941 como parte integrante dos currículos da Secção de Ciências Sociais e da de Geografia e História e em obediência ao decreto n. ${ }^{\circ} 12.038$, de $10^{\circ}$ de julho daquele ano. Os programas da Disciplina (hoje Cadeira) incluiram desde o início questões gerais e específicas de antropologia física e de antropologia cultural. O Conselho Técnico-Administrativo da Faculdade decidiu, em uma de suas sessões, que, para efeito de organização de cursos e realização de concursos, antropologia seria tomada em seu duplo aspecto: cultural e físico. A secção de Geografia e História, cujo currículo está sobrecarregado, tem apenas um ano de antropologia, de três aulas semanais, o que não basta para uma intrcdução, em nível universitário, à antropologia física e cul. tural. Tal contingência nos cbrigou a limitar o ensino, para os alunos da secção, ao da antropologia física. Entretanto, um curso de etnografia, ministrado pela Cadeira de Etnografia Brasileira e Língua Tupi-Guarani, supre de certo modo a falha decorrente da inexistência de aulas de antropologia cultural para os alunos daquela seç̧ão. Se no futuro se realizar o projeto de dividir em duas a atual secção de Geografia e História, haverá, ao que se €spera, a possibilidade de ministrar aos alunos de Geografia e aos de História também conhecimentos fundamentais de antropologia cultural. - Para os alunos de Ciências Sociais a situação atual é mais favorável; para êles há cursos de ambos os ramos da ciência antropológica.

Incluido, assim, no currículo de duas secções da Faculdade, o ensino da antropologia, para corresponder às justas expectativas, deve ser concebido, de um lado, como o de ciência afim às disciplinas histórico-geográficas e, do outro, como o de ciência sccial. Daí se depreende que, na medida do possível, os cursos não serão os mesmos para as duas secções. Tais são as possibilidades da ciência antropológica que ela, sem fugir ao seu cunho próprio e rigorosamente definido, é capaz de contribuir com proficiência para a formação especial de historiadores e géografos - que encaram os fenômenos no tempo e no espaço - e com não menor pro- 
ficiência para a do sociólogo, que os encara em têrmos de relações humanas. A orientação do ensino diferirá, por isso, nos dois casos, como haveria de diferir, ainda, se fôsse destinado a estudantes de medicina, de ciências administrativas, de psicologia, de direito ou de teologia. A Ciência do Homem permite ampliar em múltiplos sentidos o horizonte de outros especialistas que se ocupam de fenômenos humanos. E se vem merecendo cada vez mais a atenção e o interêsse dêstes, é porque os seus resultados já estão sendo por êles aproveitados. $\mathrm{Na}$ Universidade de São Paulo, aliás, a Cadeira de Antropologia estabeleceu um regime de colaboração didática, através de preleções e seminários, com cadeiras afins: Sociologia, Etnografia e Psicologia Educacional.

O estudante de Geografia e História pouco lucraria com um curso minucioso, por exemplo, de antropologia social, ao passo que não pode, por outro lado, dispensar o estudo classificatório e descritivo das formas humanas fósseis e atuais, principalmente do ponto de vista de sua distribuição pelos diferentes ambientes geográficos. Também as aulas de antropologia cultural, quando destinadas a estudantes dessa secção, encararão antes de mais nada as configurações culturais como sistemas adaptativos e de exploração dos recursos da natureza e analisarão os fenômenos de mudança cultural $\mathrm{em}$ sua seqüência cronológica e enquanto manifestações duma causalidade histótica. Diga-se de passagem que os historiadores estão hoje a tal ponto familiarizados com a atitude histórico-cultural de muitos antropólogos que chegam a proclamar, como certa vez o ouvi de Lucien Febvre: "Il faut écrire sur les murs: L'anthropologie est nôtre."

$\mathrm{Na}$ secção de Ciências Sociais, por seu turno, a orientação do ensino dará maior ênfase a questões de organização social e interação humana e às relações entre sociedade e cultura, sem que, por isso, os alunos da secção sejam dispensados do estudo da antropologia física, sob pena de perderem, o que seria lamentável, visão de conjunto do ser humano, razão de ser da própria ciência antropológica. Ademais, não deixa de ser valiosa, para o sociólogo, a compreensão das bases e condições biológicas da vida em sociedade.

Em sentido mais amplo, o problema é o da adequação dos cursos aos fins que se tenham em vista. Mesmo na atualidade, em que o sistema universitário brasileiro não conhece uma secção de antropologia, e muito menos institutos de antropologia, desdobrados em várias cadeiras, correspondentes às disciplinas que os integrem, os objetivos diretos ou imediatos são pelo menos quatro: $1^{\circ}$ ) munir os licenciados em história, geografia e ciências sociais de uma perspectiva antropológica, que lhes proporcione novas possibilidades no tratamento de seus respectivos campos de pesquisa; $2 .^{\circ}$ ) formar professôres de antropologia, que venham ocupar as cátedras universitúrias ou trabalhar junto a elas; $3 .^{\circ}$ ) formar pesquisadores competentes, que se dediquem à investigação científica dos problemas antropológicos do país; $4^{\circ}$ ) formar técnicos capazes de aplicar os conhecimentos antropológicos na solução de problemas práticos. São quatro objetivos legítimos, e diversos uns dos outros, que 
exigiriam talvez a instituição de outros tantos tipos de cursos - o que, pelo menos por enquanto, seria utópico. Façamos, pois, o possível dentro das possibilidades da organização vigente. O essencial é não nos iludirmos quanto ao grau das limitações a que estamos sujeitos, nem, por outro lado, às possibilidades de reduzi-las, se, por meio desta Reunião e de outras medidas, provarmos o papel que a antropologia pode desempenhar em benefício da coletividade, e conseguirmos que lhe seja concedido, no concêrto das atividades universitárias, o status que lhe compete.

Quanto às limitações atuais, é certo que o ensino vigente, pelo seu caráter supletivo, de matéria complementar desta ou daquela secção da Faculdade de Filosofia, Ciências e Letras, não forma antropólogos. Os próprios cursos de especialização, instituidos pela portaria ministerial n. ${ }^{\circ} 497$, de 15 de outubro de 1947 , não têm produzido os frutos desejados. Seria necessário que se criassem, já não digo institutos de antropologia, mas pelo menos secções de antropologia, que se emparelhassem com as demais abrangendo tôdas as disciplinas antropológicas e ministrando os conhecimentos indispensáveis de ciências ancilares. Seria a melhor forma de se conseguir elevação do nível do ensino e dos estudos antropológicos em nossa terra. Estes passariam do plano de um semidiletantismo para o da pesquisa sistemática e séria. E' neste ponto que coincidem os quatro objetivos acima enumerados.

Creio, pois, não ser descabido se pleiteie a instituição de uma licenciatura em antropologia em nossas Faculdades de Filosofia. Tal pretensão não seria desconhecer a situação real, nem levaria a comprometer o ensino, mas antes a elevar-lhe o nível, uma vez que haja, para os licenciados, expectativa razoável de o título thes proporcionar um meio de vida. Em outros têrmos: se a sociedade estiver em condições de empregar certo número de antropólogos para determinados fins concretos, de preferência no exercício da antropologia aplicada.

Ao contrário do que já se tem sugerido, não me parece, por outro lado, que haja conveniência em introduzir o ensino de antropologia nas escolas secundárias do país. Certo, a Ciência do Homem não deve faltar no ensino dos ginásios, colégios e escolas normais, mas não há de ser disciplina distinta, com programa próprio. Muito se terá conseguido, quando os lentes de história, de geografia, de psicologia e de outras matérias compreenderem a necessidade de orientar segundo o "eixo antropológico" a apresentação de certos setores de seus programas e de fazer compreender a seus alunos que numerosos problemas tomam aspectos inteiramente novos, quando encarados segundo a perspectiva própria da antropologia.

Em duplo sentido, a meu ver, o ensino desta deve ultrapassar a transmissão de conhecimentos e técnicas de investigação. Em primeiro lugar, pela formação duma atitude, espírito ou mentalidade antropológica, de compreensão humanística dos povos e das culturas. Em segundo, pela atenção a possíveis campos de aplicação prática do conhecimento antropológico. Quanto ao primeiro aspecto, é evidente o papel do estudo racional das culturas e dos processos culturais na superação de 
atitudes etnocêntricas e preconceitos congêneres nascidos no terreno da ignorância. O docente de antropologia transmite aos estudantes a mensagem de uma vitória sôbre barreiras inter-étnicas e, portanto, de compreensão humana. Transmite-a através dos próprios conhecimentos científicos, sem necessidade de atitudes messiânicas, sem proselitismo de ordem política ou religiosa. Obrigado sempre a encarar valores ètnicamente determinados com referência à realidade humana geral, a considerar, para usar terminologia bergsoniana, a relatividade da moral fechada em confronto com os postulados da moral aberta, a perspectiva antropológica tem evidente alcance humanístico. Esste, inclusive, contribui para firmar o status de nossa disciplina no concêrto das ciências. Também a utilização que a Unesso vem fazendo da antropologia e dos antropólogos - pouco importam as reservas que a isto se oponham - confere a conhecimentos em si objetivos um novo significado. E se neste sentido cabe à Ciência do Homem desempenhar função educativa no mundo atual, se de alguma forma lhe compete dar orientação a indivíduos e a grupos com referência a quaisquer problemas que não sejam apenas os de conhecimento puro e desinteressado, é êste um aspecto que, a meu ver, o ensino não pode ignorar.

O segundo ponto em que o ensino ultrapassa o campo científico é a aplicação dos conhecimentos à solução de problemas práticos. Trata-se da preparação técnico-profissional dos que venham a fazer da antropologia um meio de vida fora dos institutos de ensino e de pesquisa. Todavia, por paradoxal que pareça, a melhor preparação que se possa dar ao jovem especialista que se destine a cargos técnicos, é uma sólida formação teórica. Dizer isto equivale a confessar que não dispomos, por enquanto, de um corpo de ensinamentos sistematizados de antropologia aplicada e que a êste respeito nos encontramos ainda numa fase predominantemente de experimentação empírica. Quer se trate do aproveitamento do técnico pelo Serviço de Proteção aos Indios, quer pelo Conselho Nacional de Imigração, pelo Instituto Nacional de Estudos Pedagógicos ou quaisquer outros órgãos de caráter administrativo, o funcionário há de comprovar, ou não, a sua eficiência em primeiro lugar como antropólogo e em sòmente segundo como administrador. Tanto maior será a sua capacidade, quanto mais equilibrados os seus conhecimentos de todos os setores da antropologia, sem limitação a certos campos restritos ao sabor de predileções pessoais.

No próprio tratamento científico dos problemas, porém, não falta oportunidade, durante os cursos, de se discutir o alcance prático dos resultados das pesquisas e de, por outro lado, se examinar à luz das teorias. antropológicas o êxito ou o mau resultado de umas tantas medidas politico-administrativas referentes a populações tribais, leis de nacionalização cu, melhor, aculturação dirigida de imigrantes europeus ou asiáticos e assim por diante. O exame antropológico dos erros que se vêm praticando neste setor auxiliará a que de um empirismo grosseiro se passe aos poucos à formação de um corpo de princípios cientificamente fundados. 
Questão de fundamental importância é a da amplitude a se conceder, dentro das atividades didáticas da Cadeira, a elementos de disciplinas afins, cujo recurso não se possa dispensar. $\mathrm{Na}$ organização atual essa amplitude dependerá em primeiro lugar do enquadramento dos cursos no currículo de que faça parte. Sempre que possível, ajustar-se-ão os programas aos das outras disciplinas, a fim de não se perder tempo precioso que poderia, com maior proveito, ser dedicado à discussão de temas pròpriamente antropológicos. Mas a dosagem depende também das necessidades intrínsecas dos próprios programas, pois sempre será seletivo o recurso às ciências afins, delas se emprestando o que convém ao tratamento de assuntos específicos ou de determinados setores, como, por exemplo, paleoantropologia, conceito de raça e mecanismos de diferenciação racial, problema da evolução humana. Dependerá, enfim, dos conhecimentos prévios que dessas disciplinas os alunos possam ter adquirido em cursos pré-universitários. De qualquer forma, é vantajosa a colaboração didática com professôres de outras matérias: estatística, sociologia, genética, paleontologia etc.

$\mathrm{Na}$ utilização de elementos de qualquer matéria afim, deve-se mais uma vez ter em mente a própria perspectiva geral da antropologia, que em caso algum pode ser sacrificada às minudências inexpressivas de certos temas ou a interêsses científicos pessoais. Docentes de formação sociológica não raro correm perigo de transformar suas aulas em cursos de sociologia; para os que vêm do campo das ciências geográficas tudo tende a resumir-se nas relações entre os grupos raciais e o ambiente natural; os anatomistas, por sua vez, gostam de transformar a antropologia num subramo da anatomia humana. O mesmo vale para biologistas, teólogos, lingüistas, arqueólogos e assim por diante.

Para não incorrer nesse êrro, que pode ser de desastrosas conseqüências pelas lacunas de formação antropológica que deixará nos discípulos, por não thes fornecer visão global dos fenômenos humanos, razão de ser da própria antropologia, há de o professor lembrar-se sempre de que em suas explicações não pode prescindir de conhecimentos sociológicos, mas que nem por isso antropologia se confunde com sociologia; de que não é possível nem concebível a Ciência do Homem sem utilização de conhecimentos anatômicos, mas que antropologia não se identifica com anatomia.

Assim, na organização dos cursos, ter-se-á em mente, por exemplo, que antropologia não é sinônimo de genética, ciência por outro lado indispensável na discussão de numerosos assuntos antropológicos, como sejam a evolução humana, a diferenciação racial e a miscigenação. Para o antropólogo, os conhecimentos da hereditariedade e de suas leis levam a conclusões em plano diverso do que interessa ao geneticista, assumindo determinada importância e um sentido definido com vistas a questões específicas. E' semelhante o caso da biotipologia. Sem dúvida, o estudante precisa conhecer os biótipos (de expressão grupal de ordinário limitada) em sua relação com os tipos raciais, cuja investigação faz parte do objeto próprio da antropologia como ciência de grupos biológicos. 
Nem por isso o ensino da antropologia se há de reduzir ao da biotipologia, como não se reduzirá ao da anatomia, da psicologia, da sociologia, da história e de qualquer outra disciplina de cuja contribuição a Ciência do Homem se valha constantemente, sem todavia identificar as suas preocupações e, portanto, o seu objeto formal com o de algum dêsses ramos do saber.

Os dados das ciências afins são, para o antropólogo e, por conseguinte, para o professor de antropologia, elementos de que o bom didata (como o bom pesquisador) lançará mão exatamente na medida (isto é, nem mais, nem menos) em que se prestarem para os fins que tenha em vista.

Consignando sempre o justo lugar aos assuntos centrais da ciência, e apelando para outras disciplinas apenas na medida em que auxiliarão a compreender a realidade antropológica, evita-se o perigo de descambar para exposição mais ou menos feliz de assuntos marginais, bem como de dar aos colegas a impressão de se estar invadindo constantemente seara alheia e de se cuidar de uma ciência que não tenha autonomia nem objeto próprio.

E' de suma importância o reconhecimento de que a qualificação do antropólogo não coincide em todos os aspectos com a do professor de antropologia. A vastidão do campo e o número de setores em que êste se divide obrigam aquêle a especializar-se nas pesquisas que empreenda. A era de um Boas ou de um Kroeber, sábios igualmente à vcntade, digamos, na investigação de um aspecto da língua dos Tsimshian, na dos caracteres antropométricos dos judeus da Bessarábia ou da organização familial dos Dakota, está pràticamente encerrada. O antropólogo de hoje precisa concentrar-se no estudo de campos mais restritos, de determinada tribo indígena, dêste ou daquele aspecto da aculturação de imigrantes europeus ou asiáticos, de certos fatos biológicos do cruzamento racial. Por sua vez, o professor, salvo em cursos de especialização, não se furtará à tarefa, - difícil, mas de crucial importância de dar aos estudantes uma visão geral de todos os setores da antropologia, quaisquer que sejam os seus interêsses científicos pessoais. O médico incumbido da regência da Cadeira não se contentará com aulas sôbre patologia racial, assim como o indianista não se limitará à discussão das culturas ameríndias. Nessa exigência reside uma das principais dificuldades do atual ensino antropológico no Brasil, uma vez que são poucos os docentes cuja formação universitária abranja todos os setores; só com grande esfôrço pessoal são capazes de superar a falha, para não a perpetuarem por mais uma geração.

O problema é, pois, o da compreensividade da antropologia como objeto de ensino. A solução depende, entre outras coisas, da possibilidade de o catedrático dedicar o seu tempo exclusivamente às funções do cargo, sem recorrer a atividades suplementares para equilibrar o orçamento doméstico.

Poderia parecer supérflua qualquer referência ao papel dos exercícios práticos e trabalhos de pesquisa como parte integrante do ensino 
universitário da antropologia. Infelizmente, porém, tal não se dá. Casos há, e não raros, de estudantes que, ao concluirem o curso, não aprenderam nenhuma técnica de pesquisa de antropologia física ou cultural, ou não tiveram sequer oportunidade de ver um goniômetro ou um acrômetro. O menos que se deveria exigir, como complemento das preleções expositivas e das demonstrações didáticas, é que os jovens fizessem as mensurações mais importantes em seus companheiros de turma e que no fim do curso tivessem participado de pelo menos uma ou duas pesquisas de antropologia cultural. À discussão dessa ordem de trabalhos se dedicaria parte dos seminários desenvolvidos paralelamente aos cursos teóricos.

$E$ se há pouco me referi à inconveniência de certas atitudes nacionalistas, apresso-me agora $\mathrm{em}$ ressaltar a necessidade de um nacionalismo sadio nas preocupações do professor. Não adianta discutir a organização de currículos e programas, nem os princípios didáticos mais eficientes para a transmissão dos conhecimentos, nem tão pouco os requisitos essenciais ao treinamento do futuro especialista, enquanto não se conseguir que o trabalho universitário deixe de pairar no espaço, sem conexão com as realidades culturais que formam o ambiente do estudante. Por isso no Brasil o bom ensino de antropologia há de ser em primeiro lugar o da antropolcgia brasileira. O estudo das questóes metodológicas e o confronto das várias posições teóricas far-se-ão vantajosamente com referência a situações concretas com que o estudante esteja ou possa pôr-se em contacto, quer através da observação direta, quer pela experiência vivida em seu próprio meio cultural. Poucos os países que oferecem, a êste respeito, as condições propícias do Brasil, onde a multiplicidade das situações raciais e culturais fornece exemplos elucidativos para quaisquer problemas que a discussão teórica venha a suscitar.

Com facilidade o professor aproveita a vantagem que levamos, como país "novo", sôbre as nações da velha Europa. Em certo sentido, o estado de coisas parece comparável à dos chamados povos coloniais, há poucos decênios apenas objeto de investigação antropológica e hoje possuidores, êles próprios, de especialistas altamente qualificados. A inexistência duma tradição em determinado setor da vida científica pode corresponder à ausência de numerosas peias. Como quer que seja, diante da riqueza de assuntos de investigação, seria imperdoável conferir diploma de especialista em antropologia a quem não tenha escrito dissertação ou monografia, baseada, se possível, em material inédito, e colhido pelo próprio candidato. Formar antropólogos é, antes de mais nada, formar pesquisadores capazes.

Recapitulemos os pontos capitais desta exposição.

Primeiro: O ensino da antropologia é falho sempre que levado pela unilateralidade de uma teoria ou de um método em detrimento de outros que possam contribuir para a elucidação dos assuntos estudados. O professor não deve ter medo do ecleticismo.

Segundo: Mesmo quando ministrados com finalidade restrita - como, por exemplo, a de constituirem ensino supletivo para os futuros professôres secundários de sociologia, de geografia ou de história - os cur- 
sos, quer sejam de antropologia cultural, quer de antropologia física, não podem deixar de orientar-se pelo objetivo fundamental, que é a explicação científica da natureza humana. Ao mesmo tempo, porém, serão desenvolvidos com vistas aos interêsses definidos daqueles candidatos; programas destinados a estudantes de geografia serão, pois, diferentes dos que se organizarem, por exemplo, para futuros sociólogos.

Terceiro: Para a formação de antropólogos e de técnicos de antropologia são insuficientes as possibilidades existentes na atual organização de nossas Faculdades de Filosofia. Seria recomendável a criação de secções ou mesmo institutos de antropologia.

Quarto: Em vez de aferrar-se a um cientificismo estreito, o professor não desdenhará a função educativa inerente à perspectiva antropológica. Discutindo os problemas com visão humanística, previnirá abusos oriundos de dados científicos interpretados de maneira tendenciosa.

Quinto: Enquanto a antropologia aplicada não dispuser de sólida base teórica, a melhor preparação técnico-profissional que se pode dar aos jovens ainda é a formação científica sôbre base ampla, e não restrita, por exemplo, ao setor indianista, ao africanista ou a qualquer outro campo de especialização.

Sexto: A necessidade do antropólogo de constantemente, em tôdas as fases de seu trabalho, aproveitar elementos de outras ciências, por díspares que pareçam - necessidade decorrente da própria natureza de ciência de unificação e síntese - encerra o perigo de, no ensino, nem sempre se acentuar de modo inequívoco a distinção fundamental entre a cogitação antropológica e a das disciplinas afins ou apenas auxiliares ou subsidiárias. Deve-se considerar comprometido todo ensino que abandone a perspectiva antropológica geral, mesmo na discussão de assuntos particulares. Em outros têrmos: conhecimentos subsidiários não devem, em caso algum, tornar-se um fim em si.

Sétimo: Ao contrário do pesquisador, obrigado a limitar cada vez mais os assuntos que pretenda investigar, o docente enfrenta a difícil tarefa de ministrar um ensino compreensivo, que não despreze nenhum dos campos importantes da antropologia. O candidato que decida especializar-se, fa-lo-á com maior proveito sôbre a base sólida e insubstituível de conhecimentos gerais bem sistematizados.

Oitavo e último: Para conseguir que o estudo da antropologia adquira sentido para o estudante, torna-se indispensável criar nele o gôsto pela exploração antropológica do país e encaminhá-lo para as pesquisas de campo, seara de inesgotáveis possibilidades.

A forma um tanto apodíctica das opiniões aqui exaradas não remonta a nenhum dogmatismo, mas é decorrência inevitável da concisão imposta pela limitação do tempo. E' natural que muitos dos aspectos abordados pareçam a uns pontos pacíficos e a outros questões discutíveis. A intenção foi a de abrir, com a apresentação de meu ponto de vista, um debate franco e livre de problemas cuja solução - todos o reconhecem - elevará o ensino antropológico em nossos institutos universitários a um nível que esteja à altura das necessidades do país. 